\title{
Literary Education in Russia: Problems and Trends
}

\section{Elena Valentinovna Getmanskaya}

Natalia Alexandrovna Mironova

Natalia Alexeevna Popova

\author{
Moscow State Pedagogical University, 1/1 M. Pirogovskaya Str., Moscow, 119991, Russian Federation
}

\section{Doi:10.5901/mjss.2015.v6n6s1p170}

\section{Abstract}

This article provides solutions of several key pedagogical problems by means of "Literature" subject. The following questions are actualized in the pedagogical and methodological aspects: poly-ethnicity of the school audience; teaching literature in the conditions of inclusion, creating a concept of life-long literary education, the introduction of modern literature into a school course. Along with the modern pedagogical and methodological problems solutions, the work highlights that the introduction of modern content and technological innovations into the process of teaching literature does not mean abandoning the successful (as the time shows) three hundred year old tradition of literature study in the Russian school. The systematic correlation of the modern teaching literature and its historical model will maintain the continuity of literary education. The article reasonably concludes that the success of the Russian literary education is based on strong connection of innovations and special national traditions.

Keywords: humanitarian education, continuity, historical educational model, contemporary literature, essay, inclusion, dialogue of cultures, continuing education.

\section{Introduction}

The development of secondary and higher literary education in Russia largely determines the success of humanitarian education in general. The former focus on literature typical of the Russian humanitarian paradigm correlates with modern trends in education in a complex way. Among the perspective problems of literary education in Russia, which must be resolved in accord with the changing vectors of society development are, first of all:

- increasing poly-ethnicity of the audience;

- inclusion;

- creation of the concept "education during all the life";

- introduction of modern literature into a school course, which could give a powerful impetus for motivation in reading among adolescents and youth;

- $\quad$ preserving continuity of modern literary education with the historical Russian model of teaching literature.

We shall note that the above named problems and tendencies are typical not only of the Russian educational system: similar issues in those or other variants are present today in many developed countries. The solution of these problems on the Russian soil, in addition to the active introduction of methodological innovations, should be based, on a 300-year-old literature teaching tradition in Russia marked by high performance. At the same time, the Russian literary education will retain its positions, on condition of compliance with new social conditions and with challenges of the postindustrial society.

\section{Methods}

So, school literary education in Russia is facing new challenges of the time. We are talking about active migration processes that change the ethnic presentation of students in an average Russian class. The literature course gradually attains a "new" audience of students. Classes with a multinational structure are becoming the norm for many regions of Russia: in Moscow classes the average of $20 \%$ from the whole number of pupils are the children of migrants from the CIS countries: Azerbaijan, Georgia, Uzbekistan, Tajikistan, Armenia, Ukraine (Getmanskaya, 2010, 16-21). Teaching tolerance among children of school age is a complex, multi-layered task, including getting familiar with the traditions, 
culture, art and literature of other nationalities, as well as with the system of moral and ethical values of these peoples. An essential element of a Literature teacher's work in multinational classes is to implement the principle of intercultural dialogue, introduced at schools by V.S. Bibler and realized in contrasting the culture of a pupil to the Russian culture (Bibler, 1997; Bibler, 1991; Bibler, 1996).

The dialogue of cultures in the sphere of literature methodology involves the use of such methodological ways and methods as opposing and comparison of works by Russian and national authors, the use of encyclopedic material, work on the development of students' speech on the material of both Russian and other nationalities' authors' literary texts. In multi-ethnic classrooms it is important to take into account the psychology of perception of Russian literature by bilingual students, their national mentality.

In scientific-methodological research study of the realization of literary education in inclusion occupies a special place. The priority directions of the literary education development in conditions of inclusion are:

- creation of adaptive programs, methodic and process charts devoted to literature in conditions of inclusion;

- development of constructivist pedagogy ideas in inclusive literary education;

- the use of text therapy methods when working with a fiction text at the lessons of literature with students of different physiological features.

There is a clear trend in the Russian education to view the literary education as a process which has the vector kind of development: from early preschool childhood to the systematic schooling.

The determining trends of continuous literary education in modern conditions are:

- inclusion of children from early preschool years into literary education;

- training of a professionally competent pedagogue, who coordinates the phases of literary education with the age periods of personal development;

- implementing the concept of continuous literary education in the educational practice.

The challenges a contemporary teacher of literature faces are changing. We not only have, as before, to help students to acquire specific knowledge, abilities and skills, but now we also must learn to adapt, make the classical literature closer to the modern teenager's perception, to adapt it. We must explain to our students that what their ancestors were arguing about or what they suffered is essential for our time too, because the technological advances appear but people aren't changing. The bright examples of contemporary literature will become the teacher's assistants, because "between the best examples of classical and contemporary literature there are deep ideological and semantic links, which can clearly be seen in themes and problematics of the works, in their imagery and artistic peculiarities. A key to the classical text can become a literary work of the modern author" (Popova, 2014, 103).

Gradually, by the middle of the 19th century, the study of literature in high schools found a new core, a historicalliterary course, based on the best works of Russian literature. The historical basis of continuity of secondary and higher literary education in Russia is the historical-literary high school course. The new law "On education in the Russian Federation" enshrines the continuity of the separate stages of education legally. To make legislative declaration have become practical, in order not to lose the relationship of historic and modern models of teaching literature, historical and literature course must be maintained in schools. The existence of traditional literary history course and final essay will preserve the foundations of literary education in Russia.

2.1 Poly-ethnic school. Human values, timeless ideals of kindness, honour, freedom are most reliably "preserved" in fiction. In the educational standard of the Russian school, the literature of the peoples of neighboring countries is not represented by a separate section. However, the key point of modern programs is to include Russian literature into the holistic context of the world literature in the process of literary education of schoolchildren (Chertov, 2007, 3). The situation of the Russian education space most likely implies the revision of content of world literature section in the school programs, i.e. the inclusion of the neighboring peoples' literatures. In the senior classes with multi-ethnic students there is a need for the introduction of elective courses that contain reviews of modern Belarusian, Armenian, Georgian, Azerbaijani, Estonian literature.

After the collapse of the Soviet Union, unfortunately, not only political but also the cultural autonomy of peoples appeared, and for Russian school children literature of neighboring states acquired much of the terra incognito, while the national literatures today reflect the urgent problems of the present. For example, the theme of war was paid attention to by Lithuanian, Russian, Belarusian, Armenian and Georgian writers. According to critics, in most cases, it is high-quality and objective prose of national literatures representatives: a Lithuanian Ivaškâvičus ("The Green"), a Georgian Chkvanava ("Gladiators"), an Armenian Khechoyan "A Black book, a heavy beetle", etc.

The authors deprive the war some romantic character, which is fixed in the minds of some modern young people. The war is perceived by these authors as a tragedy, something absurd, imposed by the circumstances. Writers believe it 
themselves and make the reader wonder why and with whom people fight: are they fighting with themselves. War comes from a new perspective: as an absolute evil, regardless of the goals and objectives. Such works do not disunite people, but unite, highlighting the importance of a human life, depreciated by war.

A not so long ago introduced methodical term "multinational classes" or "multicultural classrooms" needs clarification: when a class can be considered multinational, what is the number of bilingual students in comparison to others? There is also a question of what should be the balance between studying the Russian literature and the literature of ethnic groups present in the audience. How to include the literature of neighboring peoples into the course of senior classes, literature considering time constraints and the programs saturation?

The principles of multiculturalism and tolerance in the teaching of literature in Russian schools have been proclaimed, but the methodical aspect (searching texts, literary parallels, ways of national expression in literature, attitude to the eternal issues from a special national viewpoint) is still a perspective. In these circumstances, the teacher of literature him/herself should become the educator and souls collector for the students in multi-ethnic classrooms.

Similar problems of multicultural literary education exist in other countries of the world. In this regard, the approach to the study of multicultural literature in the American methodic is remarkable. In one of the electronic journals of the American National Council of English teachers (National Council of Teachers of English), in 2005, an article was published under the title "Mastering the culture-aware approach in the study of multi-ethnic literature". The article was written by Yu Ren Dong, a Professor of the Department of Secondary Education and Youth at Queens College (Dong, 2005). He emphasizes that teachers cannot be experts in all cultures, at the same time, they can recognize specific features of a particular culture during the study of fiction works, belonging to this culture. It is a way of exploring the literary text from another culture which the scholar calls a culture-aware approach in the study of multi-ethnic literature (Dong, 2005, 57).

The core of comparative analysis in multinational classes should become the problem of which works of Russian literature address the problems that are close to the ideas of the work by another ethnic group, how they are accomplished artistically, if it is possible to see something nationally specific in the author's position? Texts for the matching can be offered by the teacher, while in humanitarian-oriented classes the parallels with the Russian literature can be identified by students themselves. Another essential question is: which aspects of the comparative study of these stories could form the basis for a comparative study in multinational classes? What should manifest the principle of "dialogue of cultures" V.S. Bibler on the literature lesson? First of all, it is a comparison of the authors' ideas, plot and composition analogies, language means, comparison of readers' assessment of works, historical and functional aspects of the reading, interpretations, comparison of mental decisions of universal human moral issues.

In the Russian school the culture-aware approach (principle of dialogue of cultures) is implemented in the comparative study of Russian and other nation's works. A comparative study of the literary phenomena allows to generalize ontological, conceptual, problematic-topical, genre or stylistic aspects, and at the same time to comprehend the essence of a literary work more deeply.

\subsection{Education in the conditions of inclusion}

A special place in Russian studies of literary education, is taken by constructivist pedagogical ideas, the studying of peculiarities the literary education implementation in conditions of inclusion (adaptive programs, correctional-educational activity, organization and analysis of the text in terms of inclusion, etc.), familiarity with the vocabulary of inclusive education, consideration the forms of training students with HIA (disabilities) close to inclusion, the implementation of the concepts of "association" and "including" education at the literature lessons.

Involving the children with HIA into the work with a fiction text along with normally developing students is a serious problem. This process may be the least painless at the lessons of literature, because all students are able to get emotional and aesthetic pleasure from dealing with the fiction text. It happens because the "inherent variability of the worldview typical of the art objects, diversity and activity of activities, their poly-functional nature provides the best solutions to the tasks the modern education faces" (Andreeva, 2000, 364). The question here is not only about the creation of a unified educational space for people with different physiological features, but also about the technologies of using a fiction text in conditions of inclusion. More and more often in scientific and methodological research of recent years such term as art-therapy, text-therapy, and fairy-tale therapy appear, that in the modern Russian literary education consider as methods for facilitating the improvement of creative abilities of the child and formation of a positive attitude toward the world. Teacher, using these methods, not only solves his professional tasks, but also develops the spiritual and moral potential of the individual child. 


\subsection{Preschool literary education in the context of lifelong education}

The next, equally important problem of literary education is incorporating literature as a subject into the widely accepted education paradigm of "a lifelong education". Now in Russia, the concept of a lifelong literary education, based on the methodological characteristics of education as of a continuous systematic process of learning, contributing to the literary development of the personality, is being promoted in the broad educational practice. Development of the concept of a lifelong literature education in modern conditions has its own specific characteristics, explained by the specifics of literature as an art form, by its particular ideological function in shaping and developing the personality, because art makes it possible to assign potential of culture personally and influence the human mind and behavior. When building the claimed concept a need appears to combine values and meanings of the systematic continuous literary education with the discreetness of the child's literary development. In this regard, a professionally competent pedagogue is the principal coordinator of pairing and resynchronization of literary education steps and literary development age periods. "It is the educator who must correlate the value-semantic and activity layers of a person's literary development at different levels of literary education" (Mironova, 2012, 18).

In the Act "On education in the Russian Federation" pre-primary education has become a separate level of general education (Law of the Russian Federation, 2013). A special place in the system of pre-school education is taken by the educational sphere "Reading fiction" as it's exactly "reading of serious fiction literature, according to the O.L. Kabachek, which generates extensive, lively perception of the environment, nature and life. A true work of art always addresses the images which embody the essential cultural and moral values. It makes a man watch and experience the real depths of life. The interaction of the child's soul with the moral charge of such a work staggers it, generates catharsis - a beneficial emotional explosion, helps to see the eternal things in everyday life (Kabachek, 2007).

Dealing with fiction texts from an early age contributes to the spiritual and moral development of the child, forms his humanistic attitude to the world, teaches him empathy, sympathy, participation. Fiction has a huge educational potential, which is actualized again in the modern Russian education. "One of the truths of my teaching faith is a boundless belief in the educational power of books ... A book is a mighty weapon, without it I would be dumb or tonguetied; I could not have told a young heart even a hundredth part of what has to be told and of what l'm saying. A smart, inspiring book often determines the person's fate", -V.A. Sukhomlynsky wrote (Sukhomlynsky, 1973).

The Russian humanitarian research proved the influence of fiction literature on the formation and development of the child's personality, which is explained by the fact that the "experience of great artists' attitude to life, their life views, their world picture, concentrated in their works, are transplanted by artistic perception in the viewer's consciousness, and to some extent become the content of this consciousness and guidance of his attitude to reality" (2003, Borev, 364). In modern Russian literary education methodology artistic text to preschool stage, continuing education is seen as a tool of

- development of emotional world of the child, his fantasy and imagination;

- formation of spiritual and moral foundations of personality

- development of language and communication skills.

Systematically organized appeal to the works of fiction helps children of preschool age to develop their own attitude, to the surrounding life and its values.

\subsection{The newest literature in the school course}

In line with the socio-pedagogical innovations in the sphere of literature teaching (poly-ethnicity of the audience, inclusion, "life-long education" concept) in the last decade, a subject-meaningful, methodical problem has become particularly urgent. We consider the methodological problem of studying the contemporary literature at school to be the most interesting and ambiguous nowadays. Teacher-philologists frequently ask themselves: should the teacher of literature him/herself read books by contemporary authors; is it worth to study these works at the lesson and under what circumstances is it better to do; how to find time for the new fiction works minding the constant shortage of teaching hours?

First of all, it has to be said that the modern teacher is not familiar with the latest literature. The notion of "contemporary literature" in his mind is firmly connected with another period of $70-80$-ies years of the twentieth century. And this is a purely methodological explanation: a textbook couldn't contain literature, which was not time-tested. All Russian school programs and textbooks for many years included the works of authors of the end of the last century into the section "Modern literature". These are prose writers V.P. Astafyev, Ch.T. Aitmatov, V.V. Bykov, poets A.A. Tarkovsky, N.M, Rubtsov, D.S. Samoylov, B.A.Slutsky, I.A.Brodsky, playwrights A.N. Arbuzov, A.V. Vampilov, V.S. Rozov, etc. Nowadays some contemporary literary topics have appeared in textbooks, like "Contemporary situation in literature", 
"General characteristics of the watershed era" or "Literature of the late 20th century", but the students usually don't have time to explore these final topics. The literary education of senior students is finished with studying the works about Great Patriotic War, written in the middle of the XX century.

It must be admitted that this problem is not new to the Russian methodological school, as in the 19th century there were constant debates about the inclusion of modern literature into gymnasium and university courses. In particular, the great methodists of the past - V.Y. Stoyunin, V.P. Ostrogorsky, V.I. Vodovozov - advocated the studying of the newest literature, considering that without exploring the works of their contemporaries students will get an incomplete picture of the Russian literature at the high school. The time settled a dispute between the classical study of the literature supporters and those who called for updating the courses. The Names of F.M. Dostoevsky, L.N. Tolstoy, I. S. Turgenev don't cause any questions in our days. Moreover, a modern man finds it hard to imagine the course of Russian literature without these giants of thought.

We, teachers, who work in the twenty-first century, must honestly admit that the Russian literature of the 18th and 19th centuries is getting further away from our students, the question of our pupils' perception of past epochs literature is becoming more and more urgent.

The process of awarding helps to select from a huge amount of published texts those ones which are really the best and which the teacher can discuss at a lesson of literature. In 2013, the public attention was attracted by two novelsa novel by A.G. Volos "Coming back to Panjud" and a novel by E.G. Vodolazkin "Laurus", awarded with the most prestigious literary awards. The first novel was awarded with the "Russian Booker" Prize, the second was awarded with the award "The Big Book".

The main theme of the novel by Andrei Volos is an artist and power. In the center of the plot there is the fate of the great Tajik-Persian poet Rudaki, blinded on the Khan's orders. The novel is weaved from the hundreds of stories that the disabled poet remembers, accompanied by a guide boy to his native village. Over the painful journey Rudaki tries to understand: how this tragedy happened to him, when he overlooked the imminent danger and if he could change his destiny? Rudaki's reflections and legends, shared with his young companion, prove that the questions of honour still were more valuable for him than prosperity and that the tragic final was predetermined from the beginning.

The fate of the protagonist of A.G. Volos' novel pulls the novel together with the work of Mikhail Bulgakov "Master and Margarita". Both the novels show the artist's life in a totalitarian state, it doesn't matter whether it's medieval Persia with its barbaric practices, or industrial Moscow in the middle of the twentieth century. Crooks and incompetent fools easily bypass all obstacles gaining fame and money while the real poets, facing with the cruelty and hypocrisy, are killed.

The novel of E.G. Vodolazkin is thematically close to the novel of A.G. Volos, but his main character is not a poet, but an outstanding healer, who devoted himself to serving people. Throughout the novel the protagonist several times changes his name. Each time the name change means major changes. He will try it all: and idyllic family life and dangerous wanderings, and monastic schema and pejorative humble existence. The chapters on the jurodiv times of the main character, go back to Dostoevsky's prose, to the images of Alyosha Karamazov and Sonechka Marmeladova. Matching fragments of novels by E.G. Vodolazkin "Laurel" and by F.M. Dostoevsky's "Crime and punishment" will help students understand why a person abandons his own well-being and sacrifices himself to other people, not waiting for anything in return.

In 2014, the Russian prize "A big book" was won by the novel of Zakhar Prilepin "Abode". The work is devoted to the tragic pages of Russian history, Solovetsk special camp. The camp theme is presented in the school program by works of V. Shalamov and A.I. Solzhenitsyn. Z. Prilepin's novel as if complements the topic, but it would certainly be preferable to modern schoolchildren, as the protagonist of the work is not an exhausted, overworked by back-breaking labour old man - he is almost as old as modern senior students themselves.

Artem Goryainov was sent to the camp accidentally, inadvertently finding himself involved in a family conflict, resulting in the killing of his beloved father. On the Solovetsky Islands, Artyom meets different groups of camp prisoners, each of which embodies the Russian people's fate in the twentieth century. Critics have repeatedly criticized Z. Prilepin that he had quoted too much of prose by A.I. Solzhenitsyn, V. Shalamov, B.N. Shiryaev, I.L. Solonevich. But it is rather a fortunate case for a lesson of literature since many reminiscences will enable the teacher to line up the parallels among several texts which are not even taught at school.

In the article we give only three examples of possible addressing the modern prose at the lessons of literature, choosing the most featured works of the recent years. Naturally, such parallels could be more numerous. Nowadays many methodists and philologists write about the importance of teaching literature in such a way. One of the latest works was a textbook by M.A. Chernyak (Chernyak, 2015). 


\subsection{Traditions of literary education}

At the same time, introducing modern contents and technological innovations into the teaching of literature, one cannot renounce the successful (as the time shows) 300-year-old tradition of literature study in the Russian school. The Russian education with its growing focus on western models should not lose its national specifics. In other words, the modern process of teaching literature in Russia should fix the thought - take the best from the outside and do not lose the own national specifics.

National specifics is, first of all, preserving the historical experience of teaching literature and applying it in practice. In Russia there is a 300-year-old tradition of studying literature in a regular school (since the creation of the first GreekLatin schools and Slavic-Greek-Latin Academy at the end of the 17th century). The historical dynamics of literary education in its Russian specificity was that in the initial period it was based on grammar, rhetoric's and poetic, as well as on translations of ancient Roman and ancient Greek poets' texts. And only gradually, by the middle of the 19th century, the study of literature in high schools found a new core, a historical-literary course, based on the best works of Russian literature.

The international scientific community on preservation of historical-literary course at school does not demonstrate any unity. An interesting point of view on the historical and literary approach in the Russian school is expressed by $\mathrm{E}$. Dobrenko, a professor at the University of Sheffield (England). E. Dobrenko believes that at the lessons of literature in Russia "they teach hierarchy." After Yury Tynyanov, E. Dobrenko repeats: "the history of Russian literature is organized like in the Bible, Abraham gave birth to Isaac, Isaac gave birth to Esther and so on and so on Pushkin gave birth to Lermontov, Lermontov gave birth to Gogol, Gogol gave birth to Turgenev and so on to Chekhov" ("School literature is a story of generals, 2011"). Historical and literary structure of a school course in Russia, according to the scientist, is unchangeable, canonized, and replays itself. The main professor's claim to such a structure is that, in his view, "children are first of all taught this Canon, this chronology, rather than what to do with these texts" ("School literature is a story of generals, 2011"). The authors of the article find it difficult to agree with this position. Historical-literary principle of material presentation in no way cancels a school text analysis, present at almost every lesson of literature in the contemporary Russian school. Historical-literary course, which, as E. Dobrenko thinks, breaks the "intrinsic value" of each work, studied at school, does not take but adds to the perception and comprehension of a literary text, imparted in a specific historical and cultural situation.

Returning to the historical evolution of literary education, it should be noted that continuity between modern and traditional models of teaching literature in Russia was periodically marked by significant losses. So all of the 19th century such a subject as "Literature" was mandatory for almost all departments in Russian higher education, both technical and humanitarian (the exception was the medical department) (Getmanskaya, 2014). Literature was declared and studied as the basis of higher education in almost any specialization. One must admit that this general obligation of "Literature" discipline in Russian education has been lost. Technical high school had preserved only a modest course "culture of speech", which utilitarian goal is the correction of students' speech errors.

A substantial content loss in the teaching of literature was the disappearance of the traditional school graduating essays in 2009. Prior to the introduction of the Unified State Exam in 2009, an essay was the main educational form, connecting secondary and higher literature education in Russia throughout the 19th and 20th century. A mark for the essay became the primary criterion when defining the level of the applicant's knowledge. The final essay used to verify both the level of wording skill and historical-literary knowledge. The main conditions of successful essays were: the use of a detailed list of additional manuals for the writing; individualization of the compositions topics; a deep work at the plan of the composition with a historical-literary theme (Getmanskaya, 2013,26). All three conditions demonstrated a strictly scientific approach to the form of a composition, which remained an extremely important form both at the stage of entering a high school, and later, during the studying process.

The sufficient methodological elaboration of a composition, regularity of its use in high school, covering the themes beyond the mandatory high school programs and additional literature - all this made a composition a basis for the continuing literary education in high school.

The general humanitarian topics of the essays provided strong writing skills both when studying in an institution of any specialization, and outside the walls of the high school, within the broad social responsibilities of a school graduate. The reduced levels of literary skills and of general literacy of modern secondary school graduates in absence of the graduate compositions made higher administrative authorities return to the graduation composition. The Ministry of education and science of the Russian Federation in 2014 introduced a graduation essay assessed in a "pass/no pass" regime ("History of the project," n.d.). Credit for the composition according to the new rules provides the graduate student with admission for the Unified State Exam. Thus, the historical and literary course in high school and final essay on 
literature is a historically successful traditional base on succession of secondary and higher literature education.

\section{Results}

The scientific analysis of the continuity of the historical and contemporary literary education model leads to the conclusion that continuity preservation is both a relevant and predictive task. This task largely determines the success of state education as a whole. Mechanisms of literary education continuity, relying on current processes, first of all, find their basis in existing experience, highlight the historical national achievements, demonstrate the specificity of the development of a continuous education national model. The Russian technique at the present stage is developing a model of continuous literary education, which resulted in the literary development of the child begins purposefully from a very early age.

Mechanisms of literary education continuity, building on current processes, first of all, find their basis in existing experience, highlight the historical national achievements, demonstrate the specificity of the development of a continuous educational national model. The Russian technique at the present stage is developing a model of continuous literary education, which results in the literary development of the child purposefully started from a very early age.

The most important contemporary trends of literary education in Russia are growing poly-ethnicity of the classroom audience, and as a result, development of a new, multicultural approach to studying literature. Transforming the category of cultural dialogue into an equal dialogue of literatures in the classroom, the teacher implements the principle of a single cultural and literary education, solves training and educational tasks on the material of Russian literature and other nations' literature.

Among the many problems, connected with the present teaching literature at the Russian school, stated in the article, the problem of introducing the modern literature to the students seems one of the most insignificant. However, it is necessary to acquaint students with the current literary process, otherwise the graduates will enter life with a firm conviction that Russian classical literature died long ago. At this time the large serious literature will be passing by: and not only the reader will suffer from this but also the writer, whose books will be unable to find their target. "The gap between modern literature and a school student threatens literature, leaving it without a tomorrow" (Popova, 2011, 210).

Development of the Russian literary education is going on in close correlation with the world educational trends, one of which is the experience of teaching disabled children and children with no specifics in their physical development together (education with inclusion). The Russian experience in this aspect is connected in the first place with the modern adaptive methodics and programs, as well as the methods of art therapy, text-therapy, fairy-tale therapy at the lessons of literature.

\section{Discussion}

Actualizing the main trends of Russian literary education, it should be noted that, in this sense, Russia is in the space of global problems of humanitarian education which the whole world is facing. The study of fiction literature in the Russian school is more and more closely linked with the problem of a growing poly-ethnic audience of students. At a modern lesson of literature the dialogue of cultures is transformed into an equal dialogue of literatures. The study of literary texts belonging to other nations has an aim in understanding ethnic and mental diversity of the world.

When we say that the Russian pedagogical community recognizes the thesis "education through the whole life" it involves connecting the school period of studying literature with the literary education of pre-school readers children - on the grounds of consistency and continuity.

Continuing literary education, adding a new age group (young children), also has a different capacity of its extension. It provides a unified educational space for people with different physiological features, gives rise to technologies of using artistic texts in the conditions of inclusion, when the emotional and aesthetic pleasure from a dialogue with the fiction text "belongs" to all students, regardless of their limitations in physical health.

The historical movement of Russian society gives the modern teacher-linguist a task of adapting classic literature, making it closer to a modern teenager's perception. Russian literature of the 18th and 19th centuries is moving further away from our students, and more and more urgent is the question of our students' perception of past eras literature. The bright examples of modern literature, which follow the traditions of classical prose, will assist the teacher in it because there are deep ideological and semantic interactions between them.

\section{Conclusion}

In the current situation of looking for new directions of Russian education development and broader - of defining the 
national idea - the Russian society are increasingly drawn to the potential of "Literature" as a subject. Such attention is the proof of the historically fixed, central position of literature in the Russian educational paradigm. As long ago as at the end of the 19th century an outstanding Russian educator V. P. Ostrogorsky identified the Russian literature as "an expresser of national testaments" (Ostrogorsky, 1885,110). As the science is developing, the methods and techniques of teaching literature are changing, methodology of teaching continuity is transformed. In this process it is important to rely on historically successful models of teaching literature, along with modern achievements of methodics. At the same time it is necessary to look for new ways of engaging students into literary education, one of such successful ways may be teaching the modern literature at school.

Relying on tradition, as well as the search of new contents and methodology will help to ensure the conformity and national harmony of the emerging system of continuous literary education, to become a theoretical base for the definition of modern strategies in teaching literature.

\section{References}

Getmanskaya, E. (2010). The teaching of literature in modern Russian school: the principle of ethnic tolerance. Education Sciences and Psychology,1 (16), 16-21, retrieved from www.gesj.internet-academy.org.ge.

Bibler, V.S. (1997). On the logic responsibility for the concept "dialogue of cultures"; Culture. Dialogue of cultures; Culture of the 20th century and the dialogue of cultures (p. 207-244). On the edges of cultural logic: a book of selected essays. M.

Bibler, V. S. (1991). From science to the logic of culture: Two philosophical introductions into the twenty-first century. (p. 302-374). M. H. 2. The twentieth century and being in the culture.

Bibler, V.S. (1996). A holistic concept of intercultural dialogue school. The theoretical basis of the program: [psychology-pedagogical aspect] (P. 66-73). Psychology. Science and education, 4.

Popova, N.A. (2014). A Russian Don Quixote: the quest for a character in the works of Y. Tynyanov and Z. Prilepin. The study of literature in the context of modern educational strategies. (155 p.) The XXI Golubkov reading: the materials of the international scientifically-practical conference. M.: Econ-inform.

Chertov, V.F. (2007). Secondary Schools Programme. Literature. 5-11 classes. Moscow: Education.

Dong, Y. R. (2005). Taking a Cultural-Response Approach to Teaching Multicultural Literature (P. 55-60). English Journal, 94, Retrieved January, 3, from http://www.ncte.org/journals/ej/issues/v94-3.

Andreeva, S.A. (2000). Multifunctionality of educational area subjects. "Art" as a basis for sociocultural development of pupils. (P. 97). $\mathrm{PhD}$ thesis. Tyumen.

Mironova, N. A. (2012). A lifelong literary education concept: a practice-oriented approach: monograph. (132 p) Yaroslavl: REMDER.

Law of the Russian Federation dated December 29, 2012 \# 273-FZ "On education in the Russian Federation". Moscow: Eksmo, 2013.

Kabachek, O.L. (2007). Reading as a hobby. Moscow: Russian School Library Association, professional school librarian's library, 1 (2).

Sukhomlynsky, V.A. (1973). About upbringing. (P. 157-179) Moscow, Politizdat.

Borev, Y.B. (2003). Aesthetics. Literary theory: an encyclopedic dictionary of terms (575 p.) M.: AST, Astrel.

Chernyak, M.A. (2015). Modern literature of the twenty-first century. An invitation for the dialogue. (232 p.). M.: Nauka, FLYNT.

School literature is a story of generals. Retrieved February 10, 2011. from http://www.svoboda.org/content/transcript/1864522.html.

Getmanskaya, Elena V. "Literary Education Traditions: The Continuity of Secondary and Higher Schooling". Global education magazine. Retrieved January, 11, 2014 from http://www.globaleducationmagazine.com/literacy-education-traditions-continuity-secondaryhigher-schooling/.

Getmanskaya Elena V. "History of essay in Russian education: the lost and the current". Journal of Language and Literature. - 2014; 5(4), P. 393-396. DOI: 10.7813/Ill.2014/5-4/79.

History of the project. Chronicle of the final composition returning to high school from http://sochinenie.wikivote.ru/arhiv2.

Popova, N.A. (2011). Alexander Griboyedov against Mariya Vatutina, or whether classroom teachers have to teach modern literature. Znamya, 5, 202-210.

Ostrogorsky, V.P. (1885). Lectures on the teaching of literature. (214 p.) St. Petersburg. 